\title{
Social networking and academic performance: A review
}

\author{
Tenzin Doleck ${ }^{1} \cdot$ Susanne Lajoie $^{1}$
}

Received: 13 November 2016 / Accepted: 26 April 2017

(C) Springer Science+Business Media New York 2017

\begin{abstract}
The ubiquitous use of social networking sites by students and the potential impacts of such use on academic performance are of both theoretical and practical importance. Hence, this paper addresses the question: how does the use of social networking sites influence academic performance? The present review synthesizes the empirical findings of the extant literature, via a systematic review, that examines the efforts that have been made to explicate the association between the use of social networking sites and academic performance. The review of 23 peer-reviewed papers highlights mixed findings regarding the relationship between social network use and academic performance — serving as a call for further research.
\end{abstract}

Keywords Social networking sites $\cdot$ Academic performance $\cdot$ Grade point average . Computer-mediated communication $\cdot$ Systematic review

\section{Introduction}

Recent years have witnessed a massive surge in people inhabiting socio-technological platforms such as Facebook, Twitter, Instagram, and LinkedIn, among others; such platforms typify an umbrella term called social networking sites (SNS). As can be seen in the examples presented above, SNS come in different flavors. Whilst an overabundance of definitions and descriptions of SNS exist, we adopt the definition by Ellison and Boyd (2013), who state that a social networking site is: "a networked communication platform in which participants 1) have uniquely identifiable profiles that consist of user-supplied content, content provided by other users, and/or system-level data; 2) can publicly articulate connections that can be viewed and traversed by others; and 3 )

Tenzin Doleck

tenzin.doleck@mail.mcgill.ca

Susanne Lajoie

susanne.lajoie@mcgill.ca

1 McGill University, 3700 McTavish St., Montreal, QC H3A 1Y2, Canada 
can consume, produce, and/or interact with stream of user-generated content provide by their connections on the site" (p. 158). This updated definition was proffered in light of the changes that have occurred since the initial definition was first purveyed in Boyd and Ellison (2008), which defined SNS as allowing users to: "(1) construct a public or semi-public profile within a bounded system, (2) articulate a list of other users with whom they share a connection, and (3) view and traverse their list of connections and those made by others within the system. The nature and nomenclature of these connections may vary from site to site" (p. 211).

The genesis of SNS can be found in the website, Six Degrees, launched in 1997-a couple of years before the bursting of the dot-com bubble (Boyd and Ellison 2008; Historycooperative 2015). The advent of SNS provided users with a new set of powerful affordances to draw connections and interact with others easily, and in more ways than ever before. Almost twenty years after their conception, today, one can hardly escape the reach of social networks. A plethora of SNS were born in the initial wave of the social media era. MySpace founded in 2003 (MySpace n.d.), was the most recognizable of the lot as well as the dominant social network in the early part of the era. Following on the heels of MySpace's founding, another social network, Facebook, was unveiled a year later (Investor 2016), which now reigns supreme as it houses more than a billion users (Newsroom, 2016). Undeniably, SNS such as Facebook have drastically transformed the way in which we connect, interact, engage, share, and create social ties. The proliferation of social networks arguably represents one of the most significant phenomena in the history of computer-mediated communications.

The evidence of the pervasiveness of SNS in our everyday lives is hard to miss. The number of SNS users has risen to about 2.3 billion globally, which is in parallel with the number of Internet users counting almost one-half of the global population (Kemp 2016). Likewise, nearly two-thirds of American adults now use SNS, with the figure particularly higher for young adults (90\%) (Perrin 2015). In addition to the number of users indicating the popularity of social networking, the amount of time users spend on social networking underscores the preponderance and importance of SNS to people's daily lives. According to a recent survey by Global Web Index (Mander 2015), the average user spends about $1.72 \mathrm{~h}$ per day on social networking; this figure amounts to about $28 \%$ of all online activity. Although SNS receive patronage from almost every demographic group, one such group is particularly well represented: students (Duggan 2015). SNS have undeniably become ubiquitous and integral in the lives of students (Greenhow and Askari 2015). In fact, heavy SNS use by students is regularly reported (Duggan 2015) — students spend anywhere from 30 min to over $2 \mathrm{~h}$ on Facebook per day (Kalpidou et al. 2011). The uptake of SNS by this population has naturally attracted academic interest. Given the widespread use and importance of SNS (Greenhow and Askari 2015; Manca and Ranieri 2015; Rodríguez-Hoyos et al. 2015), the issue of how they affect students is of clear relevance to educators as well as researchers, and warrants further investigation. This paper proceeds from and highlights the importance of SNS and the influences resulting from use.

Both anecdotal and empirical evidence report that users are affected by SNS. Recent scholarship has shed light on the outcomes of SNS use-with the psychosocial effects of SNS use representing the dominant concepts addressed apropos outcomes in the continually accumulating body of work. In this substantial stream of work, for example many studies examine SNS outcomes with respect to: subjective well-being and social capital (Ellison et al. 2007); life satisfaction, social trust, civic engagement, and political 
participation (Valenzuela et al. 2009); and, student engagement (Junco 2012a) to name but a few. Furthermore, many works have associated SNS use with both positive and negative socio-psychological phenomena (Kross et al. 2013; Turkle 2011; Valenzuela et al. 2009). While a majority of research in this area has developed around the positive affordances of SNS, evidence has started to surface that highlights negative influences as well. Despite the many affordances of SNS, research has associated high usage of SNS with: psychological distress (Chen and Lee 2013), lower quality of life (Bevan et al. 2014), and reduced subjective wellbeing (Kross et al. 2013), among others. But whereas the body of work examining the effects of SNS use on psychosocial outcomes is growing and generally tending towards consensus, the link between SNS use and academic outcomes remains both inadequately covered and understood.

The phenomenal popularity and pervasiveness of SNS, such as Facebook, has not escaped the attention of educational scholars, and as such, recent years have seen a concomitant rise in investigations on SNS use (Kalpidou et al. 2011); given this backdrop, it is easy to understand the motivations - particularly in the scholarshipto endorse this push. Although the body of research on SNS use is quickly expanding (Greenhow and Askari 2015; Manca and Ranieri 2015; Rodríguez-Hoyos et al. 2015), one direction of effort - connecting SNS use and various academic phenomenaremains sparsely addressed and lacking consensus (e.g., Ahn 2011; Ainin et al. 2015; Alwagait et al. 2014; Karpinski et al. 2013). Hence, an important question in this stream of research concerns the effects of SNS use on academic outcomes. Of course, much of the prior work on academic-SNS research has indeed proceeded from and focused on the link between SNS use and academic performance. However, within this stream of work, the SNS use and academic performance link is unstable and widely contested because of the mixed findings within published results (e.g., Ainin et al. 2015; Alwagait et al. 2014; Junco 2012b; Kolek and Saunders 2008; Kirschner and Karpinski 2010). Nevertheless, despite the emergent nature of this research, we believe that this review, given the rapid and continued growth of SNS use, is timely because it helps curate the published findings.

\subsection{Rationale for the review and research question}

As mentioned above, it bears emphasis that while there has been increasing interest examining the use and effects of SNS (Kalpidou et al. 2011; Rodríguez-Hoyos et al. 2015), research has thus far largely understudied the effects of SNS use on various dimensions of academic phenomena (Ahn 2011). Identifying the academic impacts of the use of SNS is essential — one that has potentially broad interest - to comprehending whether such influences are of any consequence. Given this context, we concentrate our attention on outcomes related to academic phenomena. Although most extant studies on SNS use outcomes has focused on outcomes pertaining to the psychosocial domain (Ahn 2011), a separate stream of research has started to investigate the academic outcomes of SNS use - that is, the effect of SNS use on academic performance. The SNS-academic performance nexus is an important yet insufficiently investigated topic. While previous attempts to examine the link between SNS use and academic performance exist, notably, they have mostly yielded mixed results, and still remain contested. This apparent disagreement provides both an opportunity and motivation to further study and unlock this topic - it seems, therefore, worthwhile to commission a review on this topic for 
disambiguation. Moreover, Michikyan et al. (2015) suggest that the topic deserves attention, as it is crucial to understand whether the use of SNS impacts academic performance or if changes in academic performance propel students to gravitate toward SNS. Addressing such a question is an important endeavor.

A cursory look at the recent literature examining the link between SNS and academic performance immediately highlights the existence of mixed findings. Wohn and LaRose (2014) note, "it is difficult to draw any definitive conclusions from the literature on SNS usage and academic performance" (p.159). Because of the lack of agreement, to better understand and clarify this link, a good starting point, then, is to take stock of the related work. Moreover, given the disparate findings across studies, examining these studies as a whole affords benefits such as discerning patterns, themes, recurrent ideas, and/or trends. Given the absence of a systematic literature review covering this topic, the present review aims to fill this gap in the literature by unearthing, compiling, and showcasing the extant empirical evidence apropos this topic. In accordance with the aim of the paper- to clarify the association between SNS use and academic performance-the central question addressed by this review is: what is the link between SNS use and academic performance? Thus, the goal of this paper is to explore and better understand not just how the constructs are linked, but also to find explanatory mechanisms for the association, if any.

In light of the many dimensions of SNS use, while we acknowledge that some students do use SNS for academic undertakings (Hew 2011), in this paper, we specifically narrow our focus on general SNS use - we reasoned that lumping together studies that consider the educational impact of SNS use and general SNS could lead to conflating the findings for this review, in addition to hindering the comparability of the included studies. The work on students' academic use of SNS merits its own focus and review, and thus, we exclude such works from the present review.

The remainder of the article proceeds as follows. In Section 2, we will present and expound on the review methodology. Section 3 will present the record and summary of articles included in the review along with the results of the analysis. Following this, Section 4 will discuss the findings, highlight some important limitations of the present review, and offer some suggestions for future research. Section 5 concludes the review.

\section{Review methodology}

In this section, we turn our focus to the review methodology where we cover the procedure for identifying and gathering the articles to be included in the review.

To locate and identify the available evidence base for the present review, we followed the general guidelines-for planning, conducting, analyzing, and reporting - suggested by Kitchenham (2007) for conducting a systematic search of the literature. In what follows, we provide a description of each of the steps followed in gathering the pool of studies for the present review.

\subsection{Databases searched}

To ensure that appropriate literature was captured by our search, the search process was fashioned and limited by our guiding question. Given that the topic crosscuts various fields such as education, psychology, computer-mediated communication, etc., the search strategy 
encompassed the consideration of the online database, Social Sciences Citation Index (SSCI) to locate the highest possible number of high quality available and relevant studies. The SSCI database was selected because of its coverage of the leading journals in the aforementioned fields that cover the topic of this review. The choice of such a specific database is reasonable as it is supported by a number of reviews in the field that have relied on the SSCI database as their source of published research (e.g., Shih et al. 2008; Tsai and Fan 2013).

\subsection{Search terms and protocol}

We did not specify or constrain the time span for our search because of the short lifespan of this stream of research. Search terms were drawn from the focus on SNS use and academic performance, and thus, included the combination of variants/ conceptualizations of the two terms: (1) social networking sites and (2) academic performance, using the Boolean operators "AND" and "OR". The following relevant keywords and their combinations were used during the search process:

"Social networking sites" keyword group [social networking sites; SNS; social networks; online social networks; social networking; Facebook]

"Academic performance" keyword group [academic performance; academic achievement; academic outcomes; GPA; grades]

\subsection{Inclusion \& exclusion criteria}

In order to contain the scope and ensure the appropriateness of the results of the literature search, filters using inclusion criteria were established. The following inclusion criteria were formulated: (1) the study was reported in a peer-reviewed journal article (we eschewed conference papers because they eventually tend to be reported as journal articles and at times lack the full-text — this further helped avoid the problem of double-counting of findings; moreover, since we considered literature from various fields, this restriction helped to ensure some sense of fairness in sampling); (2) the article was written in English; (3) the study investigated and focused on students' use of SNS; (4) the study specifically examined the link between SNS and academic performance; (5) the study reported research methods and provided empirical evidence on the link between SNS and academic performance; (6) the full-text of the study was available; and, (7) the study deliberately focused on general SNS use and relegated any study that considered the educational use of SNS to the excluded bracket - we reasoned that mixing studies that considered educational use of SNS use and general SNS could lead to conflating the findings for this review. Additionally, some general quality assessments for empirical works were conducted by using some representative questions for checking quantitative studies as suggested by Kitchenham (2007, p.25), for example: "Do the study measures allow the questions to be answered?"

\subsection{Search path and results}

Using the search parameters specified earlier, we searched the SSCI database for relevant articles on the topic. The search yielded an initial pool of 260 candidate 
articles. The returned pool of studies from the search was screened for availability of the abstract. We then read the abstracts of the articles and screened them for the inclusion criteria to assess suitability for inclusion for further review; in cases, where the abstract was not clear and did not contain sufficient information to judge for inclusion, the full text was read. Following the screening, a total of 37 articles were deemed to meet the inclusion criteria. After the screening process, full-text of the articles were read and vetted to ensure that the inclusion criteria were met. This screening narrowed the pool of studies down to 16 articles. Finally, we complemented our search with additional sources: 1). using the snowball method, we scanned the references of the articles to assess if any additional relevant articles slipped through the cracks of our previous search process; and, 2). employing a Google Scholar search. This complementary search resulted in 7 additional articles. Thus, at the cul-de-sac of the search process, we found ourselves with 23 total articles. The assembled corpus containing these articles was then treated as the subject of analysis for the literature review.

\section{Results}

We followed a general coding procedure to extract information-pertinent to understanding the research question - from this pool of studies. One researcher took part in the identification and coding of the articles - this is a limitation of the review, which we will revisit later in the discussion. The final corpus was read and a table was used to record and summarize the pertinent information from each of the reviewed papers, which served as the basic unit of analysis (see Table 1). We analyzed each study with the research question guiding our evaluation to generate themes and/or patterns to describe the findings. The papers were coded for several general themes such as: year of publication, venue of publication, country/region where the investigation was conducted, purpose of the study, demographic profile, research design, study context (general SNS use or specific platforms such as Facebook), independent and dependent variables, variable measurements, analysis techniques, additional influences (mediation, moderators), study findings, as well as general observations. Additionally, when we detected gaps and avenues for future research, we noted them where we deemed appropriate. The results of the coding and synthesis are presented as various subsections below which highlight some key trends and insights drawn from the studies reviewed.

\subsection{Publication trend - Temporal view of the publications}

In plotting the development of the topic under review, the initiation of the topic - in a journal — can be traced back to the work by Kolek and Saunders (2008); an indication of the recency of the topic. In response, this work immediately spurred additional work, and in the ensuing years, there has been a small, yet increasing flow-developing a steadily growing presence - of investigations stemming from efforts geared toward better explicating this topic as illustrated in Fig. 1. While the first few years had limited articles, since 2010, an overall upward trend can be seen; however, between 2012 and 2016 , there seems to have been a plateau effect with a relatively stable output of 


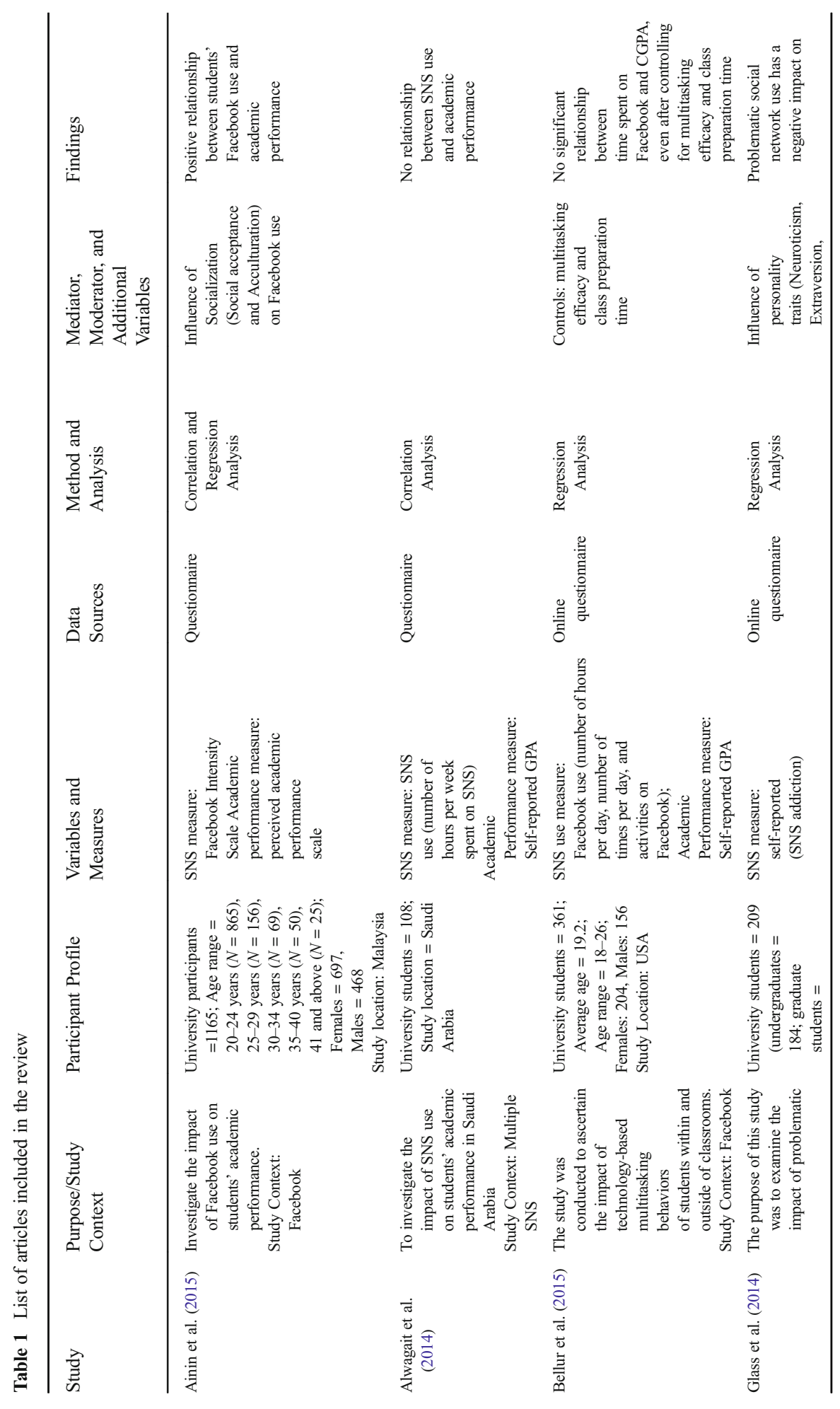




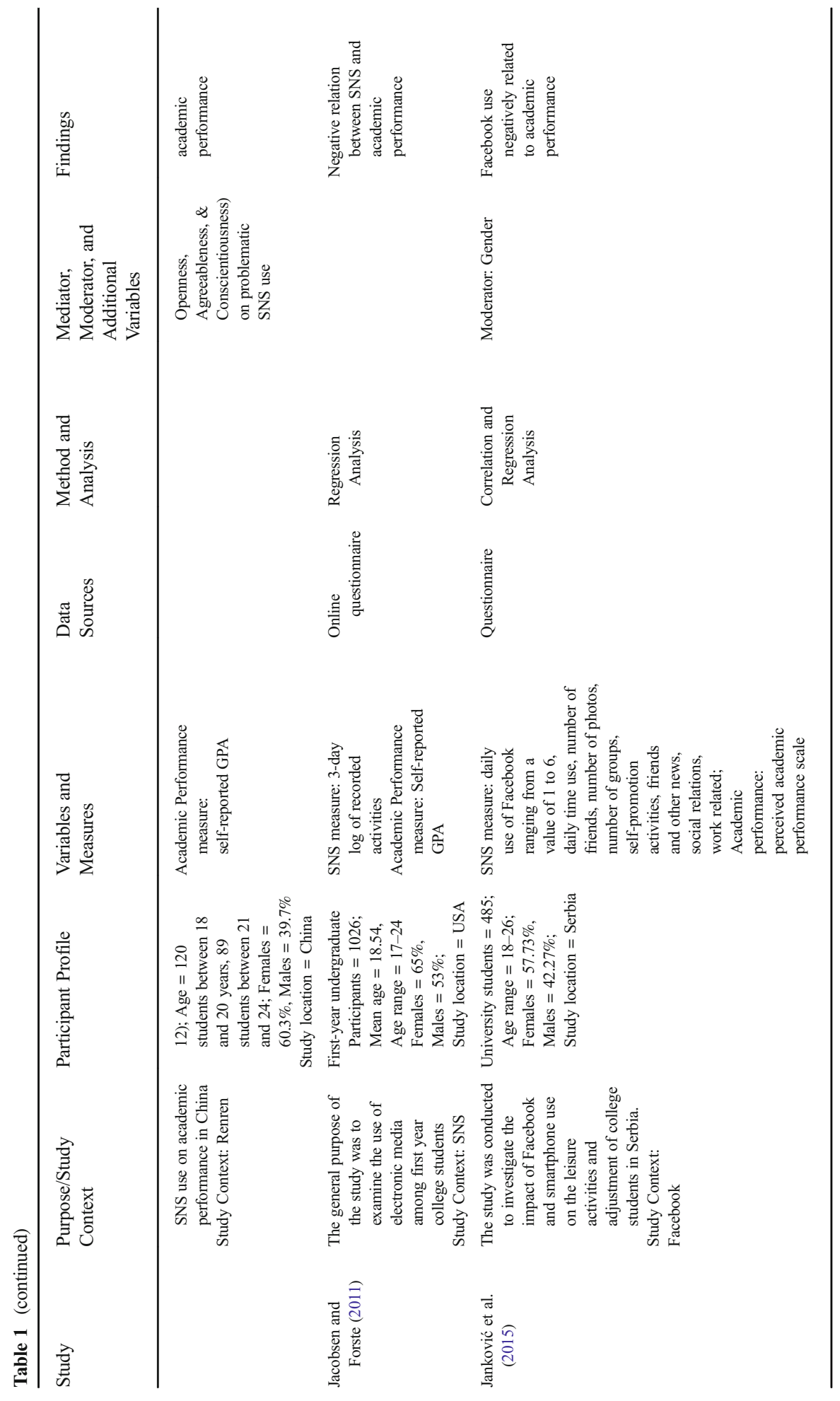




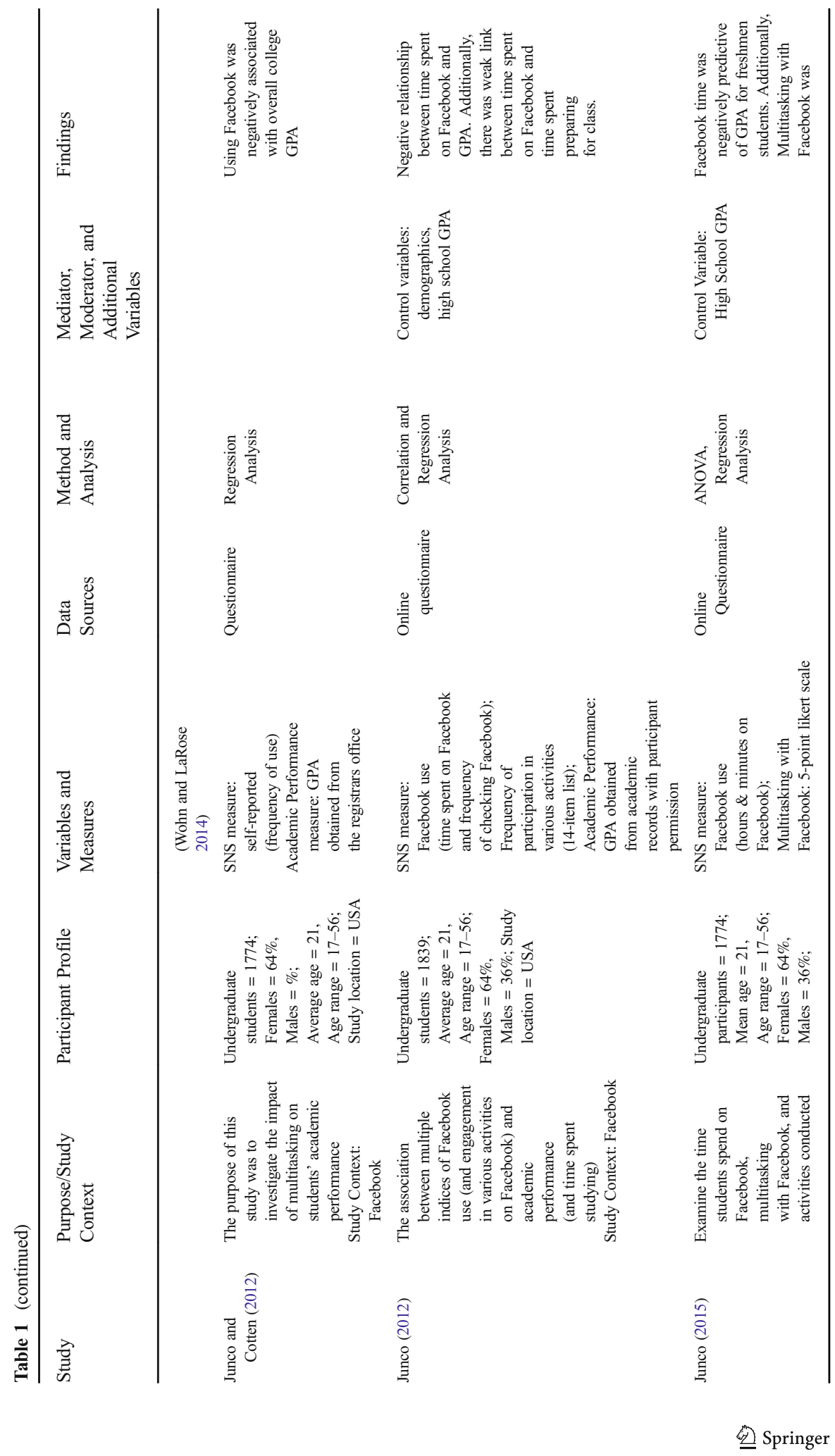




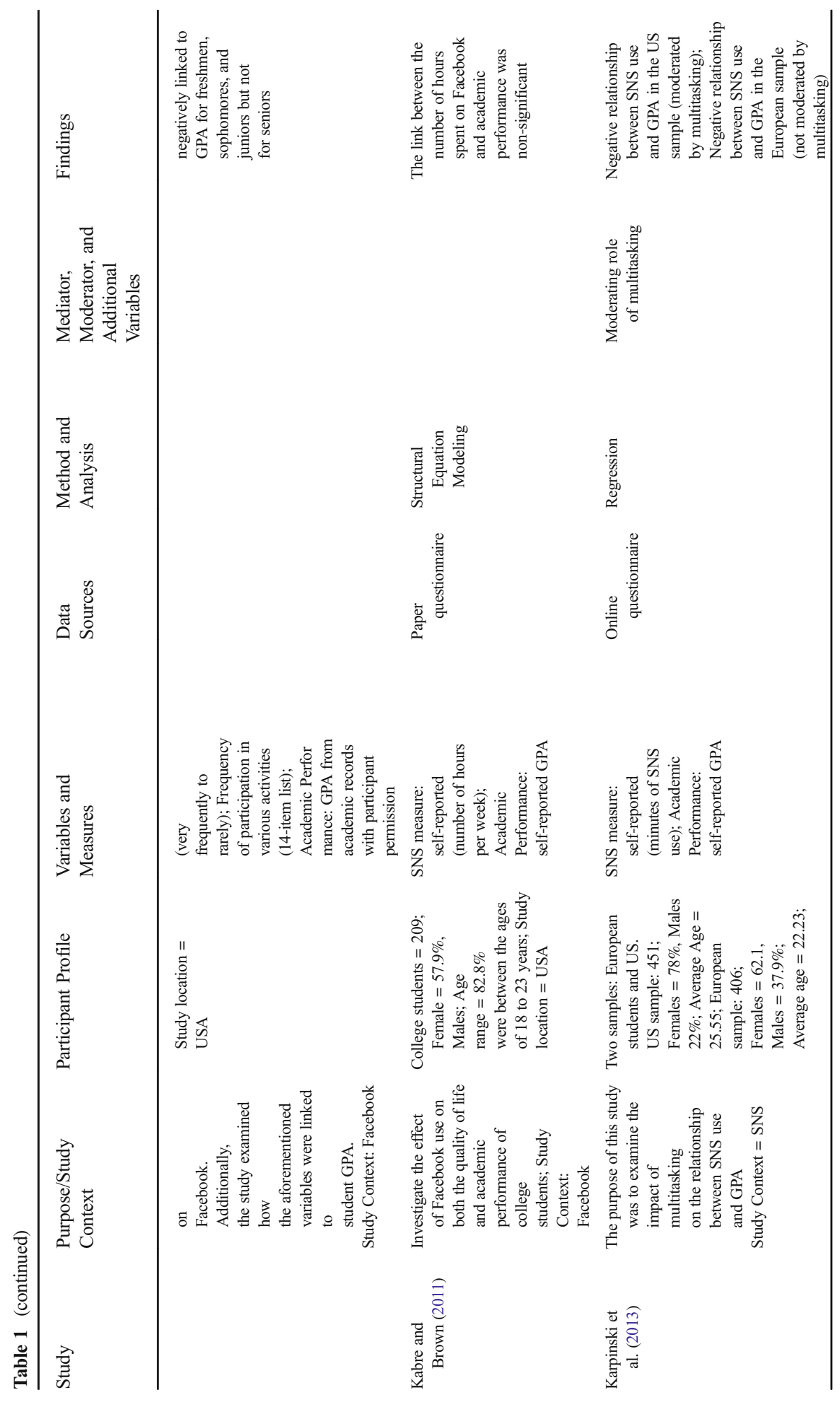




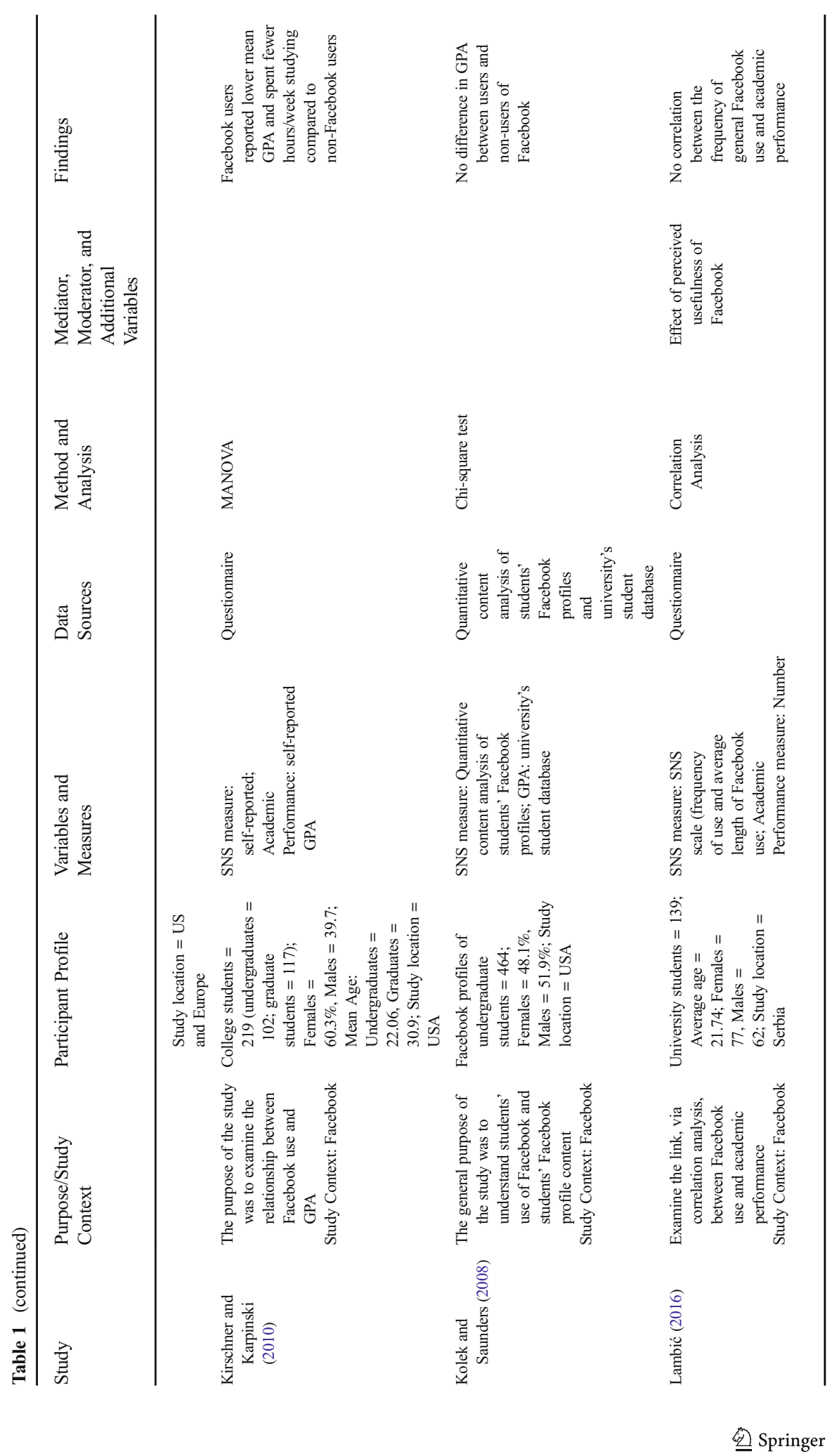




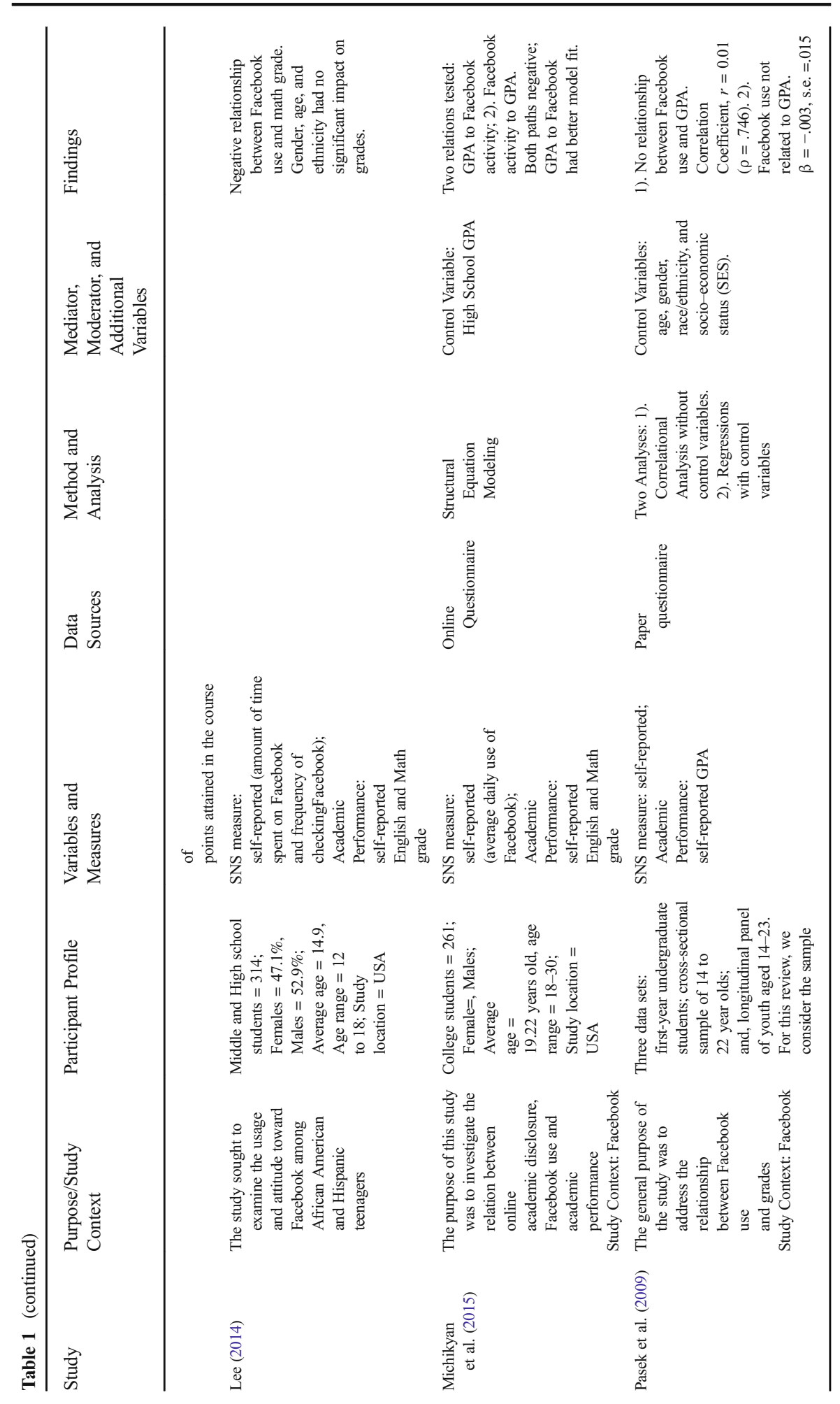




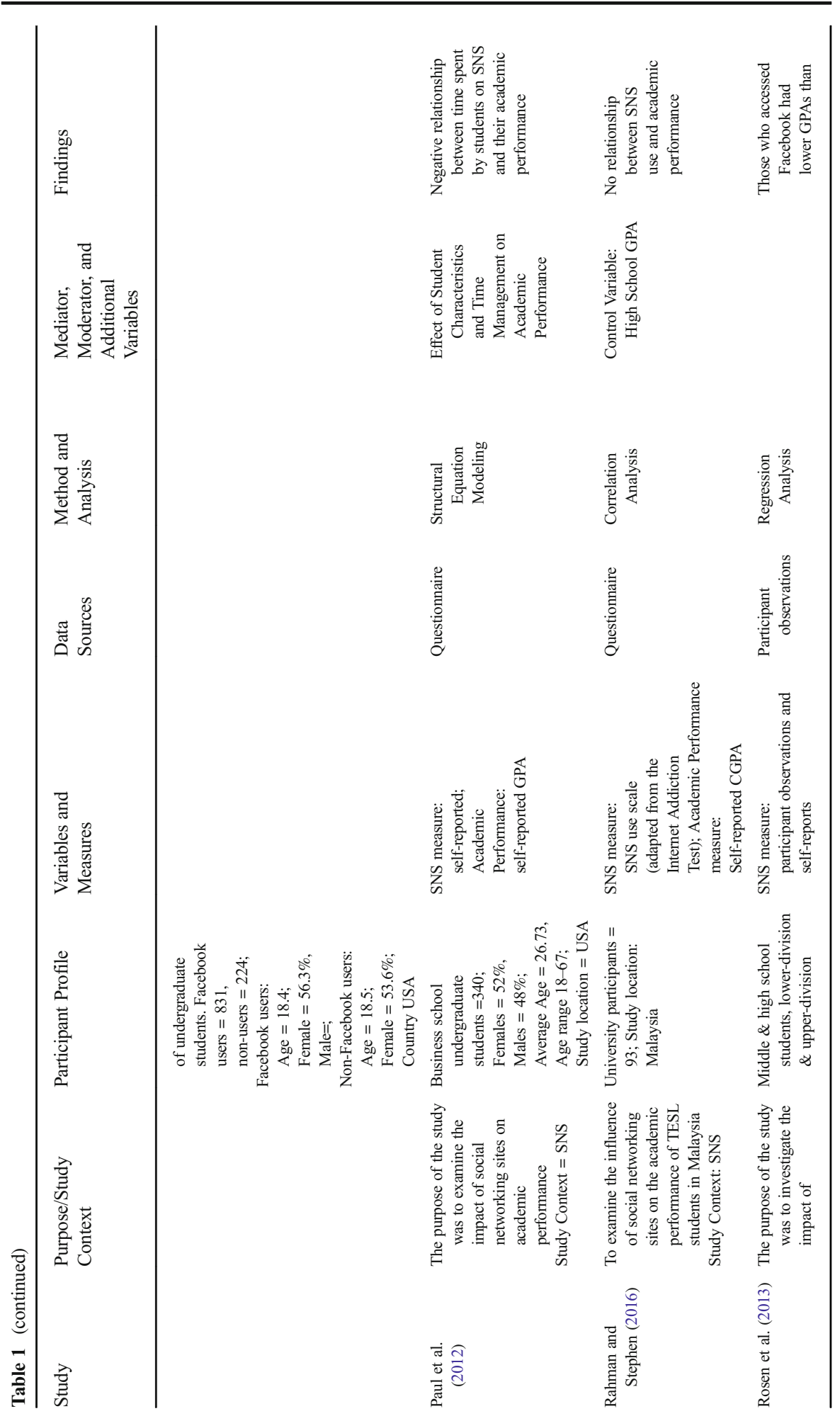




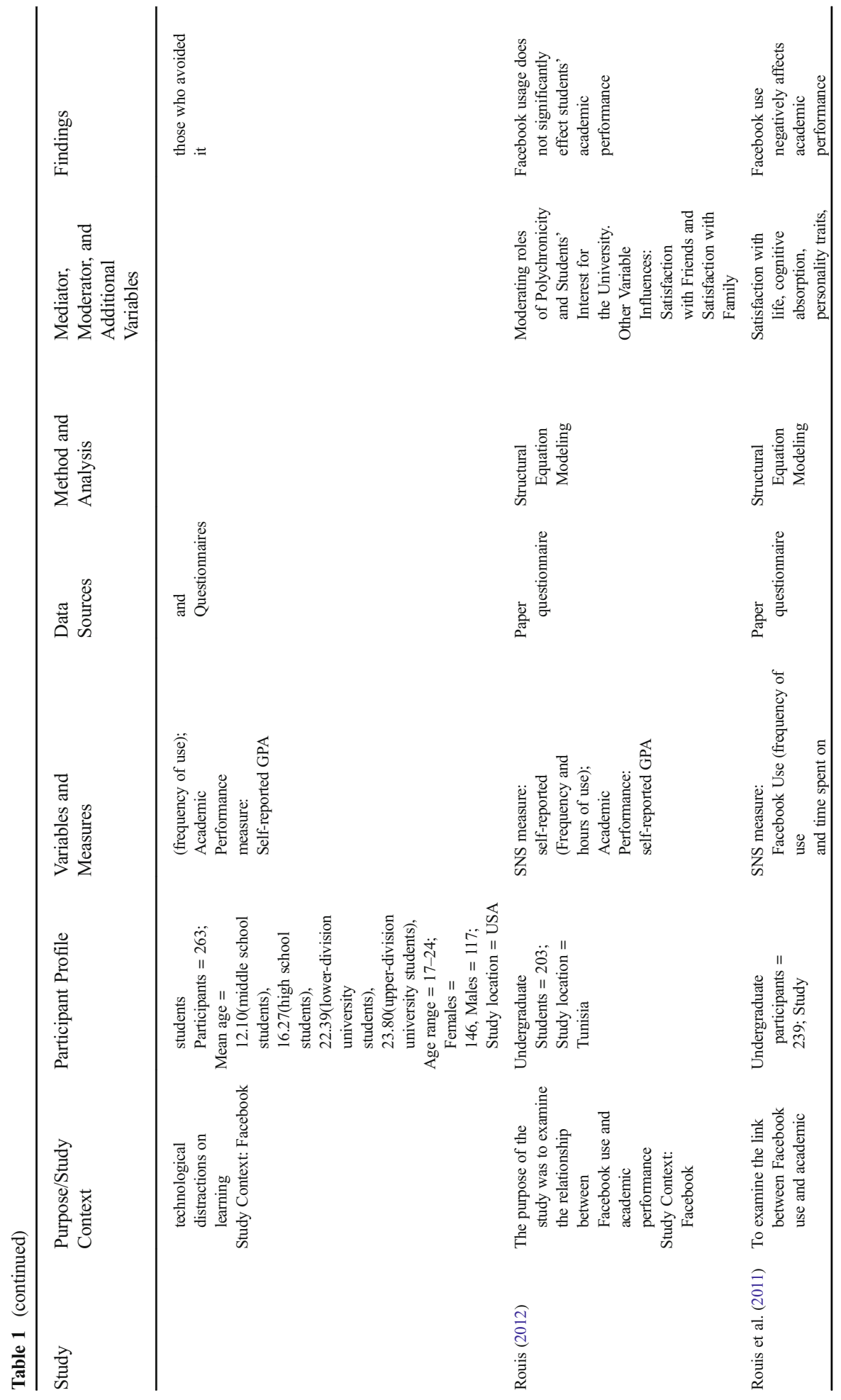




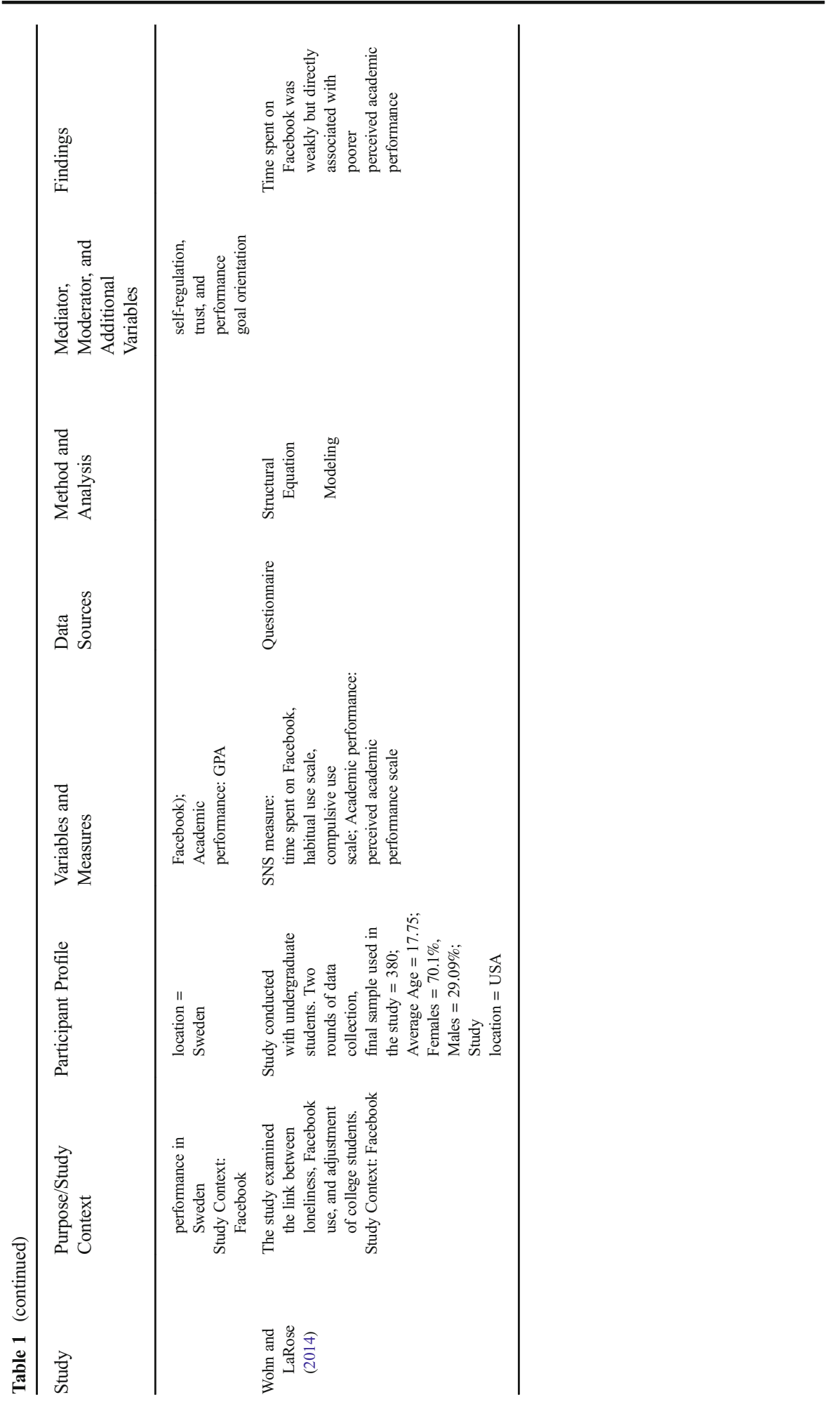




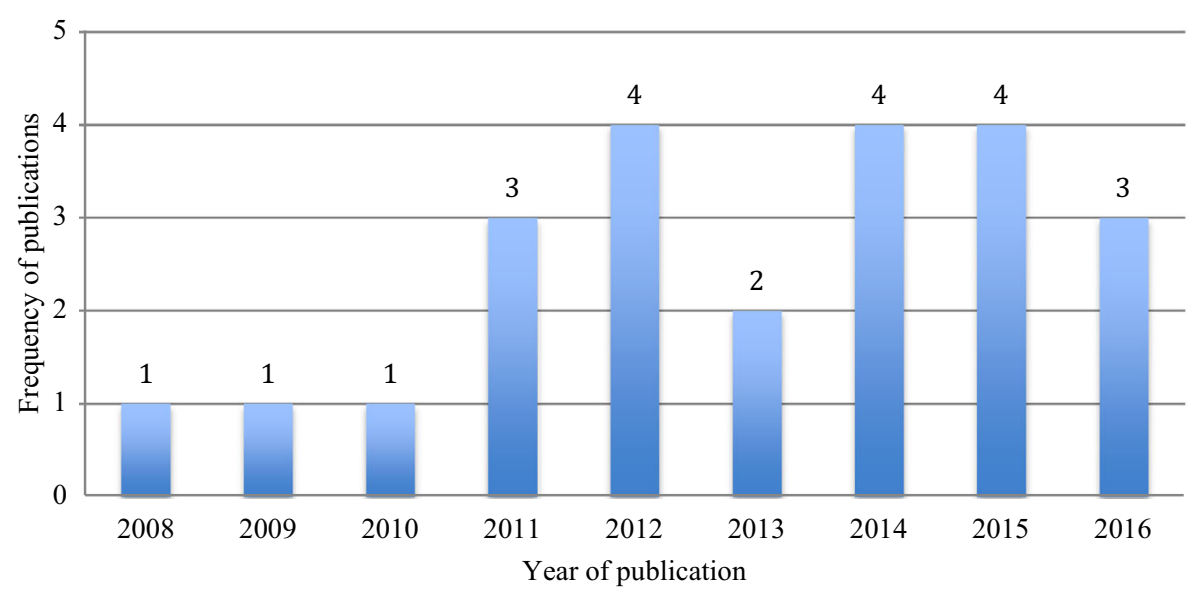

Fig. 1 Distribution of articles by year of publication

articles. Notwithstanding the fact that the number of studies is still small, yet we do see a gradual increase in the number of articles suggestive of growing interest and attention in the topic.

\subsection{Distribution of articles by journals}

A breakdown of the publications (see Fig. 2) by journals reveals that, while there was some variation in the distribution of articles by journals, much of the research we reviewed appeared in three journals, namely, Computers in Human Behavior (10 articles), followed by Computers \& Education (3 articles) and Cyberpsychology, Behavior, and Social Networking (2 articles); the remaining journals each logged one article (Electronic Journal of Research in Educational Psychology; First Monday;

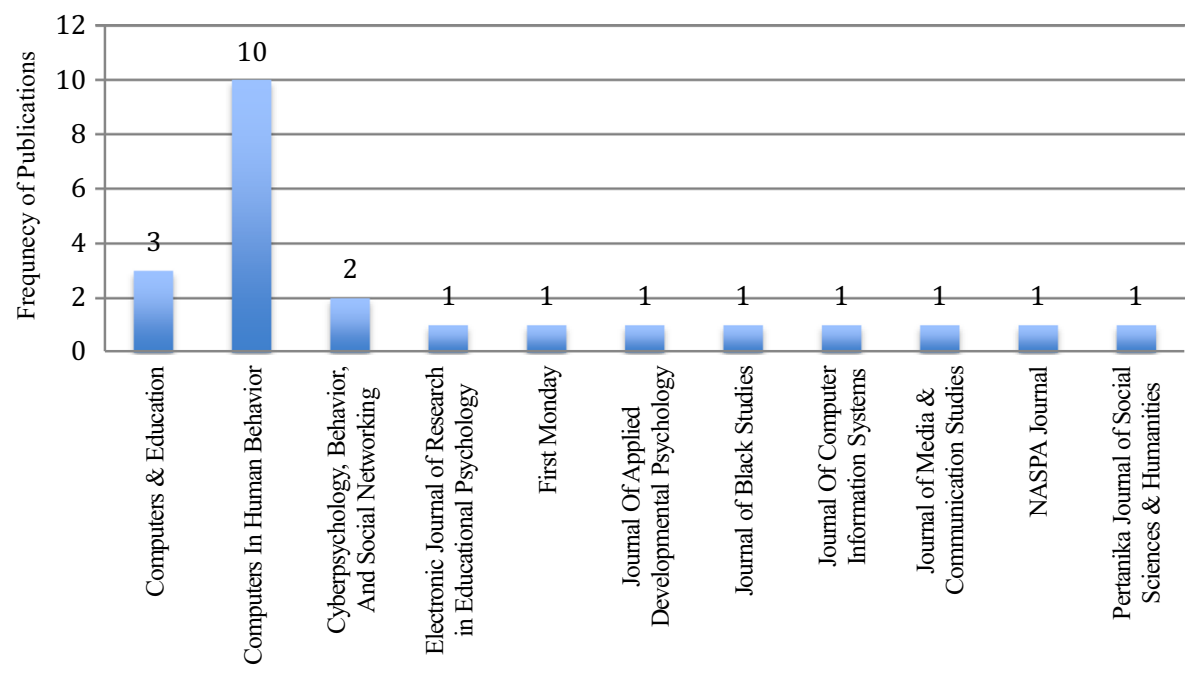

Journal

Fig. 2 Distribution of articles by journals 
Journal of Applied Developmental Psychology; Journal of Black Studies; Journal of Computer Information Systems; Journal of Media \& Communication Studies; NASPA Journal; Pertanika Journal of Social Sciences \& Humanities). Notably, almost $65 \%$ of the articles were published in just the three journals (Computers in Human Behavior; Computers \& Education; and Cyberpsychology, Behavior, and Social Networking). Yet, the distribution of articles by journals does provide some evidence for the interdisciplinary nature of the topic, covering grounds in the fields of communication, education, and psychology.

\subsection{Distribution of articles by country}

A check of the study location (countries/regions) for the published work (see Fig. 3) reveals that the majority of the studies were conducted in the USrepresenting a lion's share of the published work (Bellur et al. 2015; Jacobsen and Forste 2011; Junco, 2012; Junco 2015; Junco and Cotten 2012; Kabre and Brown 2011; Karpinski et al. 2013; Kirschner and Karpinski 2010; Kolek and Saunders 2008; Lee 2014; Michikyan et al. 2015; Pasek et al. 2009; Paul et al. 2012; Rosen et al. 2013; Wohn and LaRose 2014). The study by Karpinski et al. (2013) was conducted with samples from both the US and Europe. While it was heartening to find studies from a non-US perspective, there were only a handful of studies in other regions/countries, indicative of a relatively poor representation of non-US countries, such as from: China (Glass et al. 2014), Malaysia (Ainin et al. 2015; Rahman and Stephen 2016), Saudia Arabia (Alwagait et al. 2014), Serbia (Janković et al. 2015; Lambić 2016), Sweden (Rouis et al. 2011), and Tunisia (Rouis 2012). The skewed sample definition in regards to the geographic distribution, with the overrepresentation of US-based studies, limits the extent to which the findings generalize to the larger student population. Thus, a natural call from this is for more research from different regions/countries.

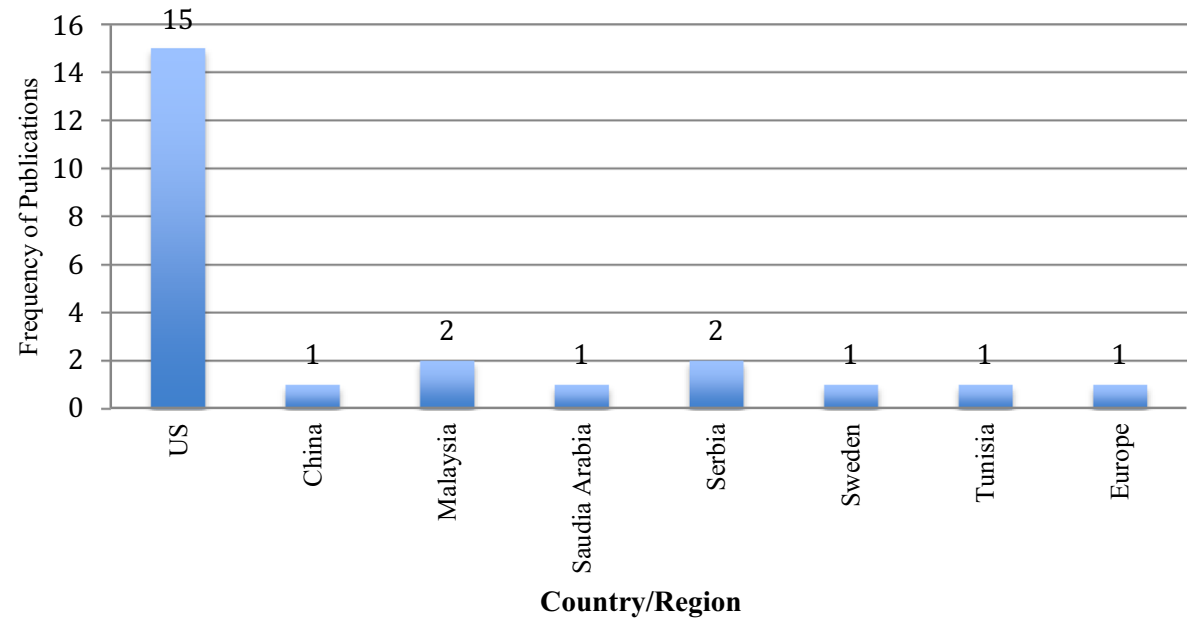

Fig. 3 Distribution of articles by study location (Note: Karpinski et al. (2013) conducted their study with samples from both the US and Europe; thus, the total (24) does not match the pool of studies in the review (23) 


\subsection{Distribution by platforms}

A large proportion of the studies focused on the use of specific platforms (see Fig. 4). Facebook was the most prominently used platform (Ainin et al. 2015; Bellur et al. 2015; Janković et al. 2015; Junco, 2012; Junco 2015; Junco and Cotten 2012; Kabre and Brown 2011; Kirschner and Karpinski 2010; Kolek and Saunders 2008; Lambić 2016; Lee 2014; Michikyan et al. 2015; Pasek et al. 2009; Rosen et al. 2013; Rouis 2012; Rouis et al. 2011; Wohn and LaRose 2014); such a disproportion should not be surprising given both the popularity of Facebook in general and on college campuses, and the increasing attention from educational researchers on the use of Facebook. Indeed, in other strands of the literature examining SNS use, there is a greater propensity for Facebook to be the choice SNS for examination (Rodríguez-Hoyos et al. 2015). Second to Facebook, in the focus across studies, was general SNS use (Jacobsen and Forste 2011; Karpinski et al. 2013; Paul et al. 2012; Rahman and Stephen 2016). Only two other studies considered platforms and/or use outside of Facebook, as well as general SNS use: Renren (Glass et al. 2014) and multiple SNS (Alwagait et al. 2014). Additionally, Facebook and smart phone usage was studied simultaneously in the study by Janković et al. (2015).

\subsection{Topics covered in the articles}

\subsubsection{Topic modeling}

Given a text corpus, such as articles in a review, it is useful to detect and recognize if there are any themes or patterns. Text mining has become a popular and useful approach for deriving information from various types of texts; one approach that facilitates extraction of topics from a collection of texts is called topic modeling (Blei and Lafferty 2009). According to Blei (2012) topic models are "algorithms for discovering the main themes that pervade a large and otherwise unstructured collection of documents" (p.1). A distinct advantage of such an automatic approach vis-à-vis human processing is the processing speed. While there are various tools that can be used to create topic models, we relied on the Latent Dirichlet Allocation (LDA) - a special case

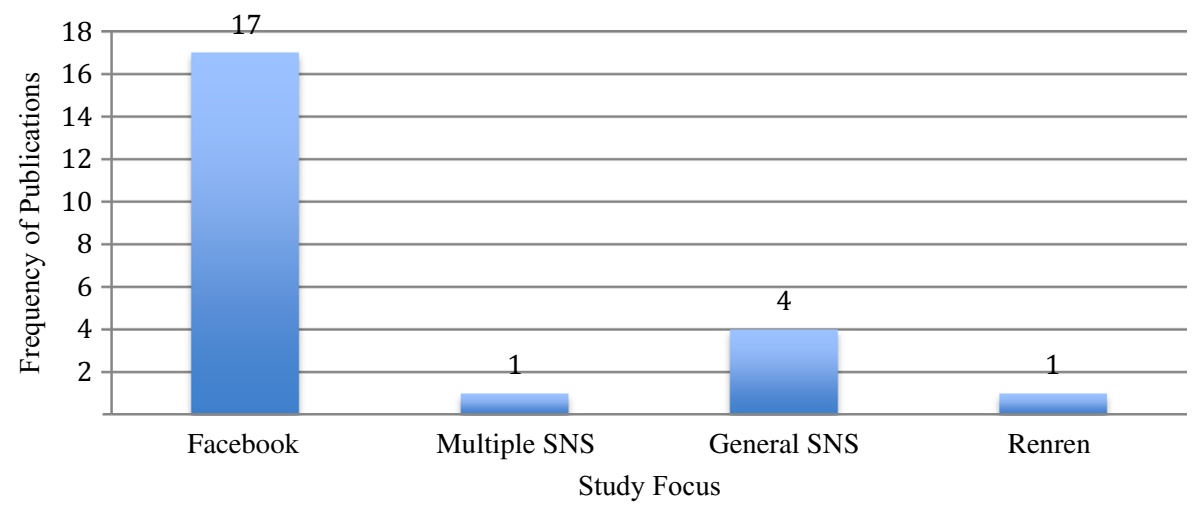

Fig. 4 Distribution of articles by platforms 
of topic modeling, as implemented in the MALLET package (McCallum 2002) - to model a corpus of articles using a topic model.

After training a topic model using MALLET, Table 2 illustrates the topics generated from the corpus, that is, the articles in the review. For the sake of brevity and the diminishing returns in the relevancy of the topics over the number of topics, we list only the five topics arranged in the order of weights assigned for each topic. For each topic in Table 2, both the weight of the topic and the words in the topic are presented. As can be seen in the first extracted topic, the words, "students academic social performance time study research relationship student computers journal found university human online negative spent results education behavior", representative of the highest weighted topic, deal with the relationship between students' academic performance and online social behavior. It is interesting that the first topic contained the word 'negative'; this is because a majority of the studies reviewed indicated a negative association between the SNS and academic performance. Turning to the second topic, the words, "facebook time gpa spent junco college class multitasking related activities frequency outcomes preparing reported school high schoolwork internet found cotten", are representative of the recent work examining the role of multitasking in the link between Facebook use and outcomes. Additionally, Junco and Cotten are the researchers spearheading this direction of work.

\subsubsection{Term co-occurrence: topic content of the article titles and abstracts}

Additional information on the topics can be discerned from techniques such as cooccurrence analysis. We rely on network visualization approach and use VOSviewer (van Eck and Waltman 2009) to analyze the topic content of the article titles and abstracts. The software provides two different map views: 1). Network visualizationprovides the results of topic clusters identified; and 2). Density visualization- illustrates the number of articles associated with each topic.

The network visualization (Figs. 5, 6, \& 7) revealed three clusters of topics: 1). Cluster 1 (academic performance, college student, facebook use, and relationship); 2).

Table 2 Topics generated by topic modeling

\begin{tabular}{|c|c|c|}
\hline Topic No. & Weight & Topic \\
\hline 1 & 1.08999 & $\begin{array}{l}\text { students academic social performance time study research relationship student } \\
\text { computers journal found university human online negative spent results } \\
\text { education behavior }\end{array}$ \\
\hline 2 & 0.25742 & $\begin{array}{l}\text { facebook time gpa spent junco college class multitasking related activities } \\
\text { frequency outcomes preparing reported school high schoolwork internet } \\
\text { found cotten }\end{array}$ \\
\hline 3 & 0.16834 & $\begin{array}{l}\text { multitasking task technology studying texting min participants class behavior } \\
\text { study phone media rosen switching homework attention text learning } \\
\text { information on-task }\end{array}$ \\
\hline 4 & 0.14903 & $\begin{array}{l}\text { facebook students learning snss frequency group aid addiction education } \\
\text { educational correlation purposes groups tesl cgpa teacher perceived } \\
\text { information knowledge subject }\end{array}$ \\
\hline 5 & 0.10183 & $\begin{array}{l}\text { multitasking sns i.e. studying gpa european minutes sample e.g. snss day } \\
\text { major users multitask qualitative hours information graduate states analysis }\end{array}$ \\
\hline
\end{tabular}




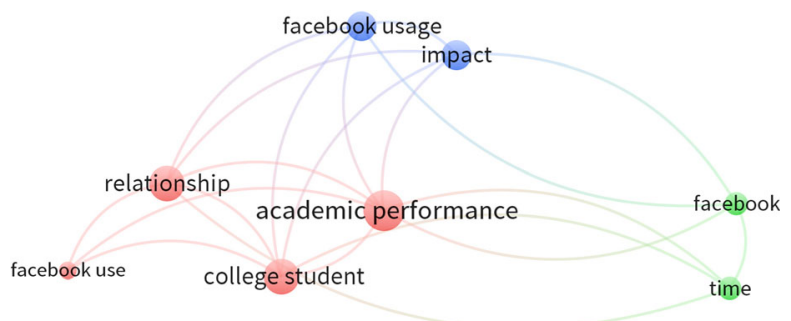

Fig. 5 Topic Clusters- Links

Cluster 2 (facebook and time); and, 3). Cluster 3 (facebook usage and impact). The network visualization illustrates the relations between the terms occurring in the corpus, with the distance between the clusters indicating general relatedness. There are two notable observations: 1). The three most frequently mentioned words are 'academic performance' 'facebook', and 'relationship'; 2). Cluster 1 is focused on the terms 'academic performance', 'college student', 'facebook use', and 'relationship'; reflecting the core topic of this review.

In the density maps (Figs. 8, 9, 10), each point is assigned a color; red indicates that the number and weights of items around a point are high in intensity, while, colors closer to blue indicate that the number and weights of the items around a point are relatively lower. Examining the occurrences in the item density maps, it is clear that 'academic performance' and 'facebook' (both indicated in red) have highest density of items around those terms.

\subsection{Methodology}

Given that we limited the scope of the review to empirical works, the methodological choices prevailing within our pool of studies were driven by and contained within the general boundaries marked for a quantitative study. Overwhelmingly, the extant literature was exploratory and cross-sectional in nature; in contrast, the distinct absence of longitudinal studies was notable. Although the cross-sectional design is widely used in practice, it also comes with some weaknesses. Hence, the nature of the approaches employed in the pool of studies precludes us from making any implications beyond the general relatedness. Further, the majority of studies relied on questionnaires for data collection. Additionally, it is worth emphasizing the differences in the methodology used in the various studies because of the influence such methodological choices exert on the outcomes of the study. The conflicting findings in the evidence base can, in part, be tracked back to such differences.

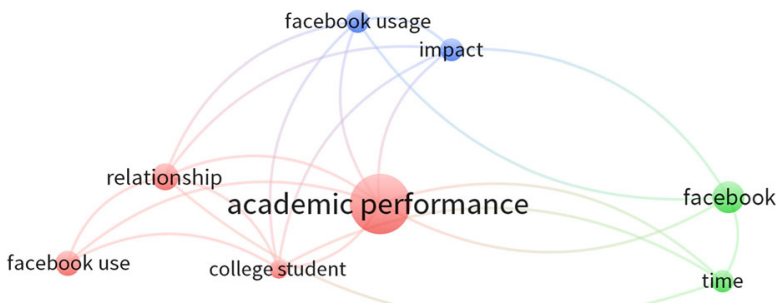

Fig. 6 Topic Clusters- Total Link Strength 


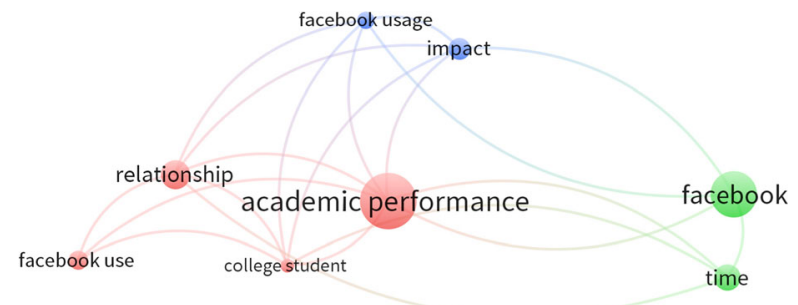

Fig. 7 Topic Clusters- Occurrences

\subsection{Setting, participants, and sample size}

In any body of literature, it is informative to understand the context in which the studies have been conducted. The majority of the studies were conducted with college/university students, as is often the case in the literature on SNS use (Rodríguez-Hoyos et al. 2015). The absence of studies focused on high school students is notable given that they represent a demographic that tends to be heavily involved in social networking. This is especially important given the reasonable assumption that the outcomes related to SNS use will differ for younger learners from the common target demographic in the literature-college students. Most of the studies reported the participant demographic variables such as gender and age. Females were better represented in the participation pool; it should be noted that females tend to more likely use SNS than males (Duggan 2015). Participants' ages were reported in most studies (Range 12 to 67). The sample sizes of the studies ranged from 93 to 1839 , revealing a large spread in the sampling across the studies.

\subsection{SNS-academic performance relationship formulation}

The extant literature mostly approaches the SNS-academic performance nexus, either explicitly or implicitly, as being linear. Additionally, the relationship between SNS use and academic performance was decidedly formulated as unidirectional from SNS use to academic performance. This suggests that the researchers have worked with this underlying presumption of the directionality of this relationship. By contrast, the yield on the other end was miniscule. Alternatively, only one study considered the relationship from academic performance to SNS use (Michikyan et al. 2015); this study calls into question the framing of the relation, and in turn contrarily suggests for a reconsideration of the directionality of the relationship. While this is reasonable to assume and opens up a new

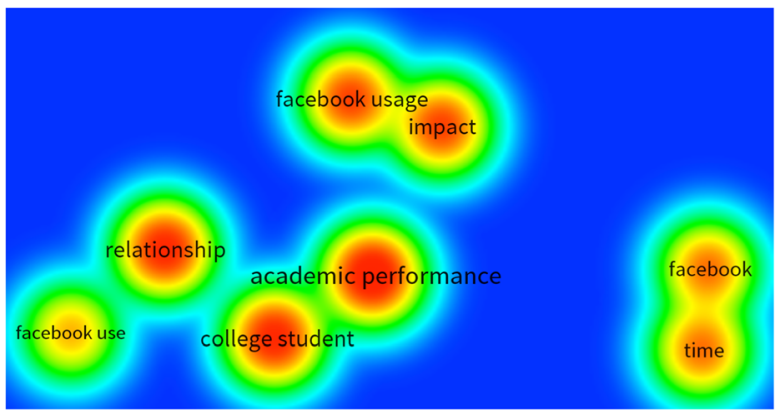

Fig. 8 Item density- Links 


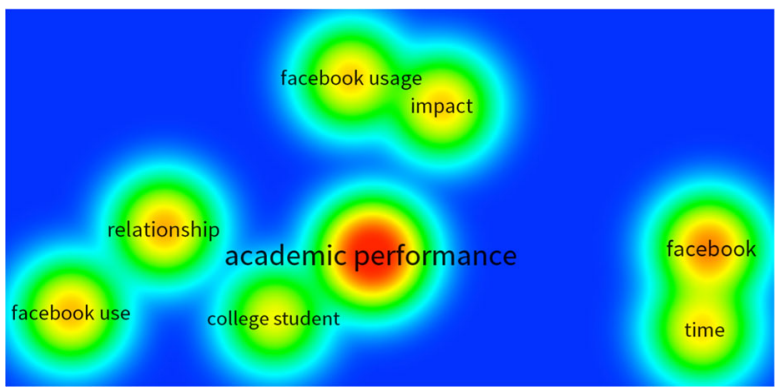

Fig. 9 Item density- Total Link Strength

lens to view the SNS-academic relationship, however, it should be noted that this study, like most studies reviewed, is also cross-sectional, so any claims on directionality should be assessed with caution. Regardless, a critical question that arises, then, is whether the formulation of the relationship proceeds from SNS use to academic performance, or vice versa. Toward this end, we suggest going beyond cross-section research, that is, that further research employing longitudinal design is required to better explain the formulation of this relationship and the temporal arrangement of the two constructs. Another possibility that proceeds from this suggestion relates to testing the reciprocal relationship between the two constructs - one that can also be tested with longitudinal design efforts.

A more recent line of thinking positions SNS use as a mediator in the relationship between social acceptance and academic performance (Ainin et al. 2015). We see such formulations deserving of extended efforts for adding to the evidence base for reconceptualization of the outcomes of SNS use. Looping back to the point about the linearity approach assumed by the reviewed studies, we contend that it may be beneficial, when relating SNS use to academic performance, to consider the potential for warped relationships as opposed to the tested relationship that has been the norm in the literaturelinear. It is worth noting that variations in findings may result from a variety of study characteristics, such as research design. Thus, the variations in the design across the studies impose some limitations in gelling the disparate evidence pieces.

\subsection{Variable construction/measurement}

There was quite a bit of variability in how researchers measured SNS use, such as: log of recorded activities (Jacobsen and Forste 2011); minutes of use (e.g., Karpinski et al. 2013); frequency and hours of use (e.g., Rouis 2012); amount of time spent on Facebook and

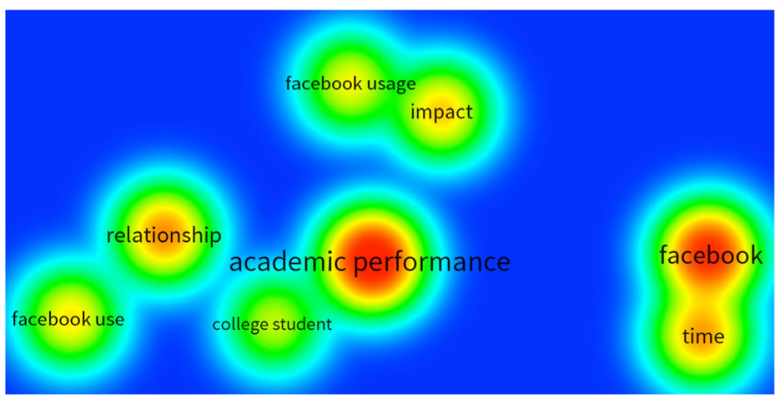

Fig. 10 Item density- Occurrences 
frequency of checking Facebook (e.g., Lee 2014); average daily use of Facebook (e.g., Michikyan et al. 2015); Facebook Intensity Scale (e.g., Ainin et al. 2015); frequency of use and average length of Facebook use (e.g., Lambić 2016); and, number of hours per week spent on SNS (e.g., Alwagait et al. 2014). The most popular measurement technique used for SNS use was self-reports. The use of self-reported SNS use seems logical and convenient given the difficulty in attaining actual usage data from users. However, measuring SNS use with the SNS scale or time on SNS is inherently deficient in that such measures fail to take into account how users' use SNS (i.e., the activities that they engage in). It is also worth noting that the way SNS use is operationalized in the literature in some ways reflects the impressive developments that have occurred with the SNS use landscape. Early works on the topic considered the use and non-use of SNS (e.g., Kirschner and Karpinski 2010; Kolek and Saunders 2008), while over time there has been a shift away from such an operationalization of use, as SNS has now become, in many ways, ubiquitous and entrenched in our lives - thus, mirroring the situation in practice. There were a few studies that employed measurement techniques different from self-reports. Rosen et al. (2013) integrated participant observations into their study, and observed the participants' use of various technologies as well as their behaviors using a studying observation form; this was complemented with a post-studying questionnaire. Another study used a log of recorded activities for measuring the time spent on SNS (Jacobsen and Forste 2011).

Junco (2013) notes that the literature on SNS use and academic performance more often than not uses GPA as the measure of academic performance. Academic performance was measured primarily via: self-reported GPA (e.g., Bellur et al. 2015), GPA obtained from registrar (e.g., Junco and Cotten 2012), and perceived performance (e.g., Ainin et al. 2015; Janković et al. 2015). Overwhelmingly, studies resorted to the use of self-reported GPA and/or perceived performance compared to actual GPA obtained from the registrar/ student records; this probably speaks to the difficulty in obtaining actual GPAs, along with the convenience that measures such as self-reported GPA and perceived performance afford in gathering data. Thus, the studies that employ such proxies suffer from limitations inherent to such use.

The conflicting and inconsistent findings in the published studies may in some fashion reflect, or even stem from, the differences in how the variables are constructed and/or measured. Davenport et al. (2014) point out that an issue with the extant research on SNS is "a lack of specification regarding the type of sites included under the umbrella of "social networking" " (p.2); furthermore, they argue that we need to reconsider the reliance on standard SNS usage variables as such efforts can be guilty of oversimplification. Additionally, Wohn and LaRose (2014) point out that the attempts to extract any decisive conclusions from the published work are complicated by the fact that "the concept and measurement of SNS usage varied across studies" (p.2). Thus, in some ways the evidence is likely muddied by the inconsistent and imprecise operationalization and methods of measurements of the constructs. Given the sensitivity of the findings to the operationalization of the variables and the variability in the designs, as pointed out earlier, one has to exercise some caution in drawing generalizations from such synthesis.

\subsection{Analysis}

Most studies presented descriptive analyses for the data. The early studies on this topic predominantly treated the analysis through correlations (e.g., Pasek et al. 2009). 
Likewise, it should be noted that a majority of the studies in the early part of the topic development used correlation analysis. This could be a function of the follower mechanism where subsequent studies simply try to follow the line of analysis conducted by the early works. Regression analysis (e.g., Junco and Cotten 2012; Rosen et al. 2013), MANOVA (e.g., Kirschner and Karpinski 2010) and structural equation modeling (e.g., Michikyan et al. 2015; Wohn and LaRose 2014) were other methods of analysis employed in the studies. Given the nature of the analysis conducted in the bulk of the studies, it is difficult to speak to the causality of the tested relationships, and as such should temper the findings of such an evidence base. It behooves us to note that given that a user can engage in various activities on SNS, analysis techniques frequented in the studies may be deficient in fully explicating such complex relationships in the absence of both context and temporality.

\subsection{Positive, negative, and/or insignificant findings}

Contradictory data points on the association between SNS use and academic performance emerged from the evidence base (see Fig. 11). On one hand, one study detected a positive relationship (Ainin et al. 2015). Likewise, Junco (2012), who despite finding a negative relationship between the time spent on Facebook and GPA, note that behaviors such as sharing links and checking on friends were positively linked to GPA. On the other hand, some studies revealed a negative relationship (Glass et al. 2014; Jacobsen and Forste 2011; Janković et al. 2015; Junco and Cotten 2012; Junco, 2012; Junco 2015; Karpinski et al. 2013; Kirschner and Karpinski 2010; Lee 2014; Michikyan et al. 2015; Paul et al. 2012; Rosen et al. 2013; Rouis et al. 2011; Wohn and LaRose 2014). Still others found no significant relationship (Alwagait et al. 2014; Bellur et al. 2015; Kabre and Brown 2011; Kolek and Saunders 2008; Lambić 2016; Pasek et al. 2009; Rahman and Stephen 2016; Rouis 2012). From this, while it may be easy to make a negative appraisal, caution is warranted given some of the issues pointed in the earlier subsections of the findings.

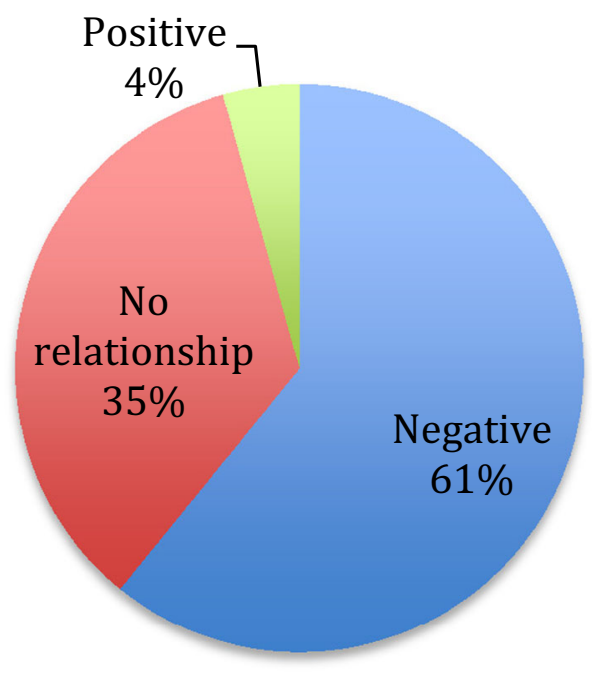

Fig. 11 Distribution of articles by findings 
Of course, there were some qualifiers in the findings that need mentioning. For instance, Junco (2013) found the negative link between time on Facebook and GPA to be significant only for freshman students. Moreover, multitasking with Facebook was negatively linked to GPA for freshmen, sophomores, and juniors, but not for seniors. While, the results still seem spotty and generally channel toward two main results (negative and no relationship), a simple frequency weighing of the studies suggests a negative bent in the association. This negative echo is in line with another strand of the literature that has examined the association between general technology use and academic performance (e.g., Wentworth and Middleton 2014). While many possible explanations have been offered, we find the one offered by Junco \& Cotten (2011) to be reasonable: engaging in SNS use "while trying to complete schoolwork may tax students' capacity for cognitive processing and preclude deeper learning" (p.1). However, such an explanation needs to be supported by additional work. Despite the strong appeal of placing a negative lens to view the relationship, still more evidence is required to assert such an outcome. Further, one cannot simply discount the counterbalancing evidence detected in the studies that provides some resistance to the negative bent. Moreover, we should also view the findings with the effects of publication bias in mind given the preponderance to publish statistically significant scientific results coupled with the publication bias against null findings (Hubbard and Armstrong 1997).

\subsection{Additional variables}

While there is apparent usefulness and reason in examining the explicit link between SNS use and academic performance, being bounded by such constraints leaves much to be elucidated. Yu et al. (2010) note that "the hidden complexity and dynamism of social networking behavior necessitates exploration of the underlying linkage mechanism between online social networking and desirable learning outcomes" (p. 3). Surprisingly, the literature has paid little attention to spillover effects of SNS use. This is, we contend, in part attributable to the narrow focus on the SNS-academic performance link. Some of the articles in the review illustrate SNS to have additional spillover influences, such as: Facebook users spend fewer hours studying per week compared to non-Facebook users (Kirschner and Karpinski 2010). Likewise, students are more likely, when faced with a lack of time, to give up academic work for Facebook use (Janković et al. 2015). In light of such disclosures, additional attempts should consider the influences of SNS use on additional variables such as study habits and study strategies to provide a more wholesome picture of the academic influences of SNS use.

Across the reviewed articles, an aspect that the studies have scantily considered is the influence of either mediators and/or moderators on the SNS-academic performance link. We suggest that additional research may examine whether a consideration of such influences can help better explicate the mechanisms underlying this link. The idea that SNS use effects academic performance was initially the go-to way of approaching this topic. However, in recent examinations, adjustments to this line of thinking have been made, as illustrated in the recent consideration of the possible mediating role of SNS use (Ainin et al. 2015). Some studies have suggested for an examination of potential influences of other variables and contextual factors on this link. In this context, there are certain salient variables that deserve consideration. Multitasking has been offered as 
a moderating variable in the link between SNS use and academic performance (e.g., Junco, 2013; Karpinski et al. 2013); however, it should be noted that both studies included some qualifiers in the findings. In the Junco (2013) study, multitasking with Facebook was negatively linked to GPA for freshmen, sophomores, and juniors, but not for seniors (suggesting the variations in findings based on the class standing of students). Likewise, the moderating role of multitasking was only significant in the US sample and not in the European sample (Karpinski et al. 2013). Another study included considerations for moderating roles of polychronicity and students' interest for the university (Rouis 2012). Thus, we view such efforts as a promising line of enquiry for the explication of this link. Additionally, some studies, such as Bellur et al. (2015) controlled for multitasking efficacy and class preparation time in their investigations. While, studies such as the one by Pasek et al. (2009) incorporate control variables, including, age, gender, race/ethnicity, and socio-economic status (SES), however, rather limited research has considered the influences of such demographic factors. Even though considerations for the influence of personality traits on SNS use was offered by a few studies (Glass et al. 2014; Rouis et al. 2011), Davenport et al. (2014), note that SNS research has tended to ignore the influences of variables such as personality. Thus, future efforts could focus on the influences of demographic factors and personality characteristics.

\section{Discussion}

We stated early in the paper that a cursory search of the literature revealed strikingly divergent findings. Having arrived at the finish line, the initial assessment has not changed. Despite the steadily growing scholarship examining the topic under consideration, the review, consisting of 23 papers, leaves us at a juncture where the guiding question posed remains unresolved and is, instead, open for further exploration and elaboration. Despite this, the review does help bring the disparate pieces and discussion together to at least provide a better picture of what researchers have been working with - offering a foundation for future efforts. While the mixed evidence base might be disheartening, the progress made so far in the explication of the topic is commendable. In view of the above, and in keeping with the short history of the evidence base, we begin the discussion by calling for the need to contextualize the influence of SNS use on academic performance, and to avoid making any sweeping generalizations from the still early literature on this topic. Rooting the argument in the bad or good influences of SNS as it relates to academic performance must be done with caution because of the ramifications such arguments may lead to-such as imposing various adherences to undercooked evidence, or worse, contributing to a narrative that overtakes the evidence. Even if one proceeds from the notion that SNS have a negative impact on academic performance, the ramifications ought to, in some ways, be rationalized by considering the various positive benefits accorded to users. Further, simply trying to draw linear and/or direct connections between the two constructs could impinge on our understanding and assessment of the influence of SNS. Guo et al. (2014) put it aptly, "there is no absolute standard to decide whether using SNSs is a good thing because it is not one dimensional" (p.2). Then, a consideration of "not [just] the intensity but the functions of SNS use" (Guo et al. 2014, p.4) might provide a broader perspective and, 
may even help tease apart the mechanics of the relationship. So while the efforts to show how the constructs are related is commendable - which is what the extant literature has and continues to do-it is also important to be able to explain the why of this particular phenomenon, and that is where the challenge lies. But whereas the review provides some developing understanding of the topic, some open questions surface.

Given the renewed recognition for the importance of non-significant findings, of note in this review is the appearance, albeit rather modest, of such findings; given that it is less frequent to find non-significant findings reported in the literature, the mere fact that such findings found home in such a small body of work is notable. While the negative stance in the evidence base of this review connects in some ways to the larger body of work examining the association between general technology use and academic performance (e.g., Wentworth and Middleton 2014), in light of the mixed evidence, further robust findings are warranted. A notable detection was the heterogeneity in the pool of studies; this we contend could be a function of the early nature of the topic and the lack of theoretical frameworks guiding the research. In the review, we see some openings for future research, which we now discuss.

Prior work has generally relied on cross-sectional design, which while helpful, only permits static explications of relationships. Future explorations should consider longitudinal designs - which has been mostly overlooked in the studies - to better capture the temporal arrangement of the two constructs and the causal effects, if any, of SNS use over time. Such extensions take on special importance as it helps alleviate any sweeping generalizations about the causality of the constructs made with crosssectional attempts. Further, the approach for examination of the relationship has generally been from SNS use to academic performance; Michikyan et al. (2015) flipped the script and suggested a reexamination of the relationship in the other direction. Such an alternative view, while seemingly anomalous, is interesting in that it provides a new perspective on the formulation of the relationship, and thus, deserves careful consideration to gain deeper insights. Rodríguez-Hoyos et al. (2015) note that the literature on SNS use by students has highlighted that students generally tend to use SNS for social and/or recreational purposes; by contrast, others have noted that students do engage in activities that can be "academic" (Hew 2011). Thus, future efforts could examine the effects of students' use of SNS as platforms for educational endeavors and assess if there is any value add in such activities, and consequently what the influence of such use is on academic performance. We acknowledge that different SNS have different features and are used differently; thus, providing a direction for future research that could examine the SNS-academic performance nexus for individual platforms. Most studies did not report the length of experience and the number of SNS memberships that the participants had; this review reveals a need for additional research that considers the influence of such contextual factors. The existing work has generally only presented the influence of SNS on academic performance in terms of how one construct is related to another; thus, additional work is warranted to better explicate the mechanisms through which the SNS-academic performance nexus function. Another challenge in this stream of work as identified by Jacobsen and Forste (2011) relates to the difficulty in distinguishing "between various types of media use in order to estimate associations with academic performance" (p.275); thus, highlighting the complication in boxing the influence of SNS on academic outcomes. As pointed out in the literature, inconsistencies in findings begin to surface when a phenomenon is tested in cross- 
cultural contexts, which may be attributable to cultural, technological, and economic differences (Teo et al. 2017). Given the preponderance of investigations in the US, it is crucial to address this question in more diverse settings and contexts. As an illustration, Karpinski et al. (2013) tested the role of multitasking as a moderating variable in the link between SNS use and academic performance - the evidence suggested that the moderating role of multitasking was only significant in the US sample and not in the European sample. The review also found that a notable missing angle concerned the lack of approaches that leverage theoretical frameworks to investigate the link. We may be well served by future efforts that are guided by relevant theoretical groundings. Finally, given the recent calls encouraging scholars to consider replicating published studies (e.g., Makel et al. 2012; Maxwell, Lau, \& Howard, 2015), we agree that the topic would benefit from replication studies as, "research findings require replication because of their influence, not despite it" (Makel et al. 2012, p.5). Maxwell, Lau, and Howard (2015) go one step further and exhort that "that multiple replication studies will often be needed to resolve apparent inconsistencies in the literature" (p.495).

Given the emergent nature of this stream of work, it is difficult to pin a particular explanation for the elusiveness of an accordant answer to the question of the association. Likewise, drawing any strong conclusions may be hasty in light of both the short innings and little generalizable evidence that the topic enjoys. In line with this, we contend that time and accumulating investigations in this stream of work ought to help reconcile the apparent tension in the findings that this review has detected. With that, it also behooves such a review to highlight the caveats attached to this review-we hope that offering these limitations can also provide some leverage and openings for future research. Of course, the data collection method employed in this review may not have fully captured all the relevant articles; such a possibility is a natural concern. On a related point, we focused on the general use of SNS and the link to academic performance; such an emphasis may have led to exclusion of some articles of peripheral relevance. Furthermore, our strict inclusion criterion of only using peer-reviewed journal articles constrains the representation of findings; other publication types could be worth considering for expanding the review tent to provide a broader perspective on the topics. Likewise, we should also note that since we only reviewed published work, the potential for publication bias must be considered. As such, before distilling any hard insights from the review, we caution readers to be cognizant of an important caveat attached to this review which concerns the representative, not exhaustive, nature of the endeavor. The present review focused strictly on empirical works, and thus, suffers from the lack of complementary insights on both the qualifications and contexts afforded by qualitative studies. Furthermore, a single author conducted the literature search and coding of the articles; future review efforts could benefit from having multiple eyes and perspectives to strengthen the rigor of this research.

\section{Conclusion}

The goal of this review was to focus on the literature linking SNS use and academic performance. The up-to-date review of 23 studies examining the link is expected to provide an accumulated and coherent understanding to help guide the debate, and move the efforts directed at unlocking the mechanics of this link. To our guiding question- 
what is the link between SNS use and academic performance? - the review highlights an inability of researchers, so far, to arrive at an accordant answer related to the exact nature of the examined link. Researchers in this emergent stream of work have not yet reached a consensus, which may be a function of the early exploratory juncture of this scholarship and/or the complexity of this phenomenon. We agree with Kirschner and Karpinski (2010), who note that the "investigation of this phenomenon is difficult due to the methodologies involved and definition and measurement of the variables of interest" (p. 1240). Additionally, there is a lack of nuanced understanding of the explanatory mechanisms for the relationship between SNS use and academic performance, thus, supplicating for additional specific analyses that draw on the recognition of the limitations of the extant scholarship. A key takeaway from our review, then, is that - notwithstanding the contributions of the extant studies - the disagreement in the scholarship provides immense opportunities for further theoretical and empirical research to help push forward our understanding.

\section{References}

Ahn, J. (2011). The effect of social network sites on adolescents' social and academic development: Current theories and controversies. Journal of the American Society for Information Science and Technology, 62(8), 1435-1445. doi:10.1002/asi.21540.

Ainin, S., Naqshbandi, M., Moghavvemi, S., \& Jaafar, N. (2015). Facebook usage, socialization and academic performance. Computers \& Education, 83, 64-73. doi:10.1016/j.compedu.2014.12.018.

Alwagait, E., Shahzad, B., \& Alim, S. (2014). Impact of social media usage on students academic performance in Saudi Arabia. Computers in Human Behavior, 51, 1092-1097. doi:10.1016/j.chb.2014.09.028.

Bellur, S., Nowak, K., \& Hull, K. (2015). Make it our time: In class multitaskers have lower academic performance. Computers in Human Behavior, 53, 63-70. doi:10.1016/j.chb.2015.06.027.

Bevan, J., Gomez, R., \& Sparks, L. (2014). Disclosures about important life events on Facebook: Relationships with stress and quality of life. Computers in Human Behavior, 39, 246-253. doi:10.1016/j. chb.2014.07.021.

Blei, D. (2012). Probabilistic topic models. Communications of the ACM, 55(4), 77. doi:10.1145/2133806.2133826.

Blei, D., \& Lafferty, J. (2009). Topic models. In A. N. Srivastava \& M. Sahami (Eds.), Text mining: Classification, clustering, and applications (pp. 71-93). Boca Raton: CRC Press.

Boyd, D., \& Ellison, N. (2008). Social network sites: Definition, history, and scholarship. Journal of Computer-Mediated Communication, 13(1), 210-230. doi:10.1111/j.1083-6101.2007.00393.x.

Chen, W., \& Lee, K. (2013). Sharing, liking, commenting, and distressed? The pathway between Facebook interaction and psychological distress. Cyberpsychology, Behavior, and Social Networking, 16(10), 728734. doi:10.1089/cyber.2012.0272.

Davenport, S., Bergman, S., Bergman, J., \& Fearrington, M. (2014). Twitter versus Facebook: Exploring the role of narcissism in the motives and usage of different social media platforms. Computers in Human Behavior, 32, 212-220. doi:10.1016/j.chb.2013.12.011.

Duggan, M. (2015). The demographics of social media users. Pew Research Center: Internet, Science \& Tech. Retrieved 21 September 2016, from http:/www.pewinternet.org/2015/08/19/the-demographics-of-socialmedia-users/.

Ellison, N., Steinfield, C., \& Lampe, C. (2007). The benefits of Facebook "friends:" social capital and college students' use of online social network sites. Journal of Computer-Mediated Communication, 12(4), 11431168. doi:10.1111/j.1083-6101.2007.00367.x.

Ellison, N., \& Boyd, D. (2013). Sociality through social network sites. In W. H. Dutton (Ed.), The Oxford handbook of internet studies (pp. 151-172). Oxford: Oxford University Press.

Glass, R., Li, S., \& Pan, R. (2014). Personality, problematic social network use and academic performance in China. Journal of Computer Information Systems, 54(4), 88-96. doi:10.1080/08874417.2014.11645726.

Greenhow, C., \& Askari, E. (2015). Learning and teaching with social network sites: A decade of research in K-12 related education. Education and Information Technologies. Advance online publication. doi:10.1007/s10639-015-9446-9. 
Guo, Y., Li, Y., \& Ito, N. (2014). Exploring the predicted effect of social networking site use on perceived social capital and psychological well-being of Chinese international students in Japan. Cyberpsychology, Behavior, And Social Networking, 17(1), 52-58. doi:10.1089/cyber.2012.0537.

Hew, K. (2011). Students' and teachers' use of Facebook. Computers in Human Behavior, 27(2), 662-676. doi:10.1016/j.chb.2010.11.020.

Historycooperative (2015). The History of Social Media | History Cooperative. Retrieved 28 September 2016, from http:/historycooperative.org/the-history-of-social-media/.

Hubbard, R., \& Armstrong, J. (1997). Publication bias against null results. Psychological Reports, 80(1), 337. doi:10.2466/pr0.80.1.337-338.

Investor (2016). FAQ - Facebook. Retrieved 28 September 2016, from http://investor.fb.com/faq.cfm.

Jacobsen, W., \& Forste, R. (2011). The wired generation: Academic and social outcomes of electronic media use among university students. Cyberpsychology, Behavior, And Social Networking, 14(5), 275-280. doi:10.1089/cyber.2010.0135.

Janković, B., Nikolić, M., Vukonjanski, J., \& Terek, E. (2015). The impact of Facebook and smart phone usage on the leisure activities and college adjustment of students in Serbia. Computers in Human Behavior, 55, 354-363. doi:10.1016/j.chb.2015.09.022.

Junco, R. (2012a). The relationship between frequency of Facebook use, participation in Facebook activities, and student engagement. Computers \& Education, 58(1), 162-171. doi:10.1016/j.compedu.2011.08.004.

Junco, R. (2012b). Too much face and not enough books: The relationship between multiple indices of Facebook use and academic performance. Computers in Human Behavior, 28(1), 187-198. doi:10.1016/j. chb.2011.08.026.

Junco, R., \& Cotten, S. (2012). No a 4 U: The relationship between multitasking and academic performance. Computers \& Education, 59(2), 505-514. doi:10.1016/j.compedu.2011.12.023.

Junco, R. (2015). Student class standing, Facebook use, and academic performance. Journal of Applied Developmental Psychology, 36, 18-29. doi:10.1016/j.appdev.2014.11.001.

Kabre, F., \& Brown, U. (2011). The influence of Facebook usage on the academic performance and the quality of life of college students. Journal of Media \& Communication Studies, 3(4), 144-150.

Kalpidou, M., Costin, D., \& Morris, J. (2011). The relationship between Facebook and the well-being of undergraduate college students. Cyberpsychology, Behavior, And Social Networking, 14(4), 183-189. doi:10.1089/cyber.2010.0061.

Karpinski, A., Kirschner, P., Ozer, I., Mellott, J., \& Ochwo, P. (2013). An exploration of social networking site use, multitasking, and academic performance among United States and European university students. Computers in Human Behavior, 29(3), 1182-1192. doi:10.1016/j.chb.2012.10.011.

Kemp, S. (2016). We Are Social's comprehensive study of digital, social and mobile usage around the world (pp. 1-537). We are social. Retrieved from http://wearesocial.com/uk/special-reports/digital-in-2016.

Kirschner, P., \& Karpinski, A. (2010). Facebook and academic performance. Computers in Human Behavior, 26(6), 1237-1245. doi:10.1016/j.chb.2010.03.024.

Kitchenham, B. (2007). Guidelines for performing Systematic Literature ReviewsinSoftware Engineering (EBSE Technical Report). Retrieved from https://www.cs.auckland.ac.nz/ mria007/Sulayman/Systematic_ reviews 5 8.pdf.

Kolek, E., \& Saunders, D. (2008). Online disclosure: An empirical examination of undergraduate Facebook profiles. NASPA Journal, 45(1), 1-25. doi:10.2202/0027-6014.1905.

Kross, E., Verduyn, P., Demiralp, E., Park, J., Lee, D., Lin, N., et al. (2013). Facebook use predicts declines in subjective well-being in young adults. PloS One, 8(8), e69841. doi:10.1371/journal.pone.0069841.

Lambić, D. (2016). Correlation between Facebook use for educational purposes and academic performance of students. Computers in Human Behavior, 61, 313-320. doi:10.1016/j.chb.2016.03.052.

Lee, E. (2014). Facebook use and texting among African American and Hispanic teenagers: An implication for academic performance. Journal of Black Studies, 45(2), 83-101. doi:10.1177/0021934713519819.

Makel, M., Plucker, J., \& Hegarty, B. (2012). Replications in psychology research: How often do they really occur? Perspectives on Psychological Science, 7(6), 537-542. doi:10.1177/1745691612460688.

Manca, S., \& Ranieri, M. (2015). Implications of social network sites for teaching and learning. Where we are and where we want to go. Education and Information Technologies. Advance online publication. doi:10.1007/s10639-015-9429-x.

Mander, J. (2015). Daily time spent on social networks rises to 1.72 hours. Globalwebindex.Net. Retrieved 10 October 2016, from https:/www.globalwebindex.net/blog/daily-time-spent-on-social-networks-rises-to1-72-hours.

McCallum, A. (2002). Mallet: a machine learning for language toolkit [Computer software]. Available from http://mallet.cs.umass.edu. 
Michikyan, M., Subrahmanyam, K., \& Dennis, J. (2015). Facebook use and academic performance among college students: A mixed-methods study with a multi-ethnic sample. Computers in Human Behavior, 45, 265-272. doi:10.1016/j.chb.2014.12.033.

Myspace (n.d). About Myspace. Retrieved 28 September 2016, from https://myspace.com/pressroom/aboutmyspace.

Pasek, J., More, E., \& Hargittai, E. (2009). Facebook and academic performance: Reconciling a media sensation with data. First Monday, 14(5). doi:10.5210/fm.v14i5.2498.

Paul, J., Baker, H., \& Cochran, J. (2012). Effect of online social networking on student academic performance. Computers in Human Behavior, 28(6), 2117-2127. doi:10.1016/j.chb.2012.06.016.

Perrin, A. (2015). Social Media Usage: 2005-2015. Pew Research Center: Internet, Science \& Tech. Retrieved 19 September 2016, from http:/www.pewinternet.org/2015/10/08/social-networking-usage-2005-2015/.

Rahman, S. H., \& Stephen, J. (2016). OMG (oh my grade)! Social networking sites ruin my academic grades? Pertanika Journal of Social Sciences \& Humanities, 24(1), 483-494.

Rodríguez-Hoyos, C., Haya, I., \& Fernández-Díaz, E. (2015). Research on SNS and education: The state of the art and its challenges. Australasian Journal of Educational Technology, 31(1), 100-111.

Rosen, L., Carrier, L., \& Cheever, N. (2013). Facebook and texting made me do it: Media-induced task-switching while studying. Computers in Human Behavior, 29(3), 948-958. doi:10.1016/j.chb.2012.12.001.

Rouis, S., Limayem, M., \& Salehi-Sangari, E. (2011). Impact of Facebook usage on students' academic achievement: Role of self-regulation and trust. Electronic Journal of Research in Educational Psychology, 9(3), 961-994.

Rouis, S. (2012). Impact of cognitive absorption on Facebook on Students' achievement. Cyberpsychology, Behavior, And Social Networking, 15(6), 296-303. doi:10.1089/cyber.2011.0390.

Shih, M., Feng, J., \& Tsai, C. (2008). Research and trends in the field of e-learning from 2001 to 2005: A content analysis of cognitive studies in selected journals. Computers \& Education, 51(2), 955-967. doi:10.1016/j.compedu.2007.10.004.

Teo, T., Doleck, T., \& Bazelais, P. (2017). The role of attachment in CEGEP students' use of Facebook. Interactive Learning Environments. Advance online publication. doi:10.1080/10494820.2017.1315602.

Tsai, C., \& Fan, Y. (2013). Research trends in game-based learning research in online learning environments: A review of studies published in SSCI-indexed journals from 2003 to 2012. British Journal of Educational Technology, 44(5), E115-E119. doi:10.1111/bjet.12031.

Turkle, S. (2011). Alone together: Why we expect more from technology and less from each other. New York: Basic Books.

Valenzuela, S., Park, N., \& Kee, K. (2009). Is there social Capital in a Social Network Site?: Facebook use and college Students' life satisfaction, trust, and participation. Journal of Computer-Mediated Communication, 14(4), 875-901. doi:10.1111/j.1083-6101.2009.01474.x.

van Eck, N., \& Waltman, L. (2009). Software survey: VOSviewer, a computer program for bibliometric mapping. Scientometrics, 84(2), 523-538. doi:10.1007/s11192-009-0146-3.

Wentworth, D., \& Middleton, J. (2014). Technology use and academic performance. Computers \& Education, 78, 306-311. doi:10.1016/j.compedu.2014.06.012.

Wohn, D., \& LaRose, R. (2014). Effects of loneliness and differential usage of Facebook on college adjustment of first-year students. Computers \& Education, 76, 158-167. doi:10.1016/j. compedu.2014.03.018.

Yu, A., Tian, S., Vogel, D., \& Chi-Wai Kwok, R. (2010). Can learning be virtually boosted? An investigation of online social networking impacts. Computers \& Education, 55(4), 1494-1503. doi:10.1016/j. compedu.2010.06.015. 